\title{
Odporność na korozję wżerową napoin ze stopu Alloy 59 w syntetycznym roztworze FGD
}

\author{
Pitting corrosion resistance of padding welds made from Alloy 59 \\ in "Green Death" solution
}

\section{Streszczenie}

W artykule przedstawiono wyniki badań odporności na korozję wżerową napoin z nadstopu niklu Alloy 59 w syntetycznym roztworze, symulującym środowisko pracy charakterystyczne dla skruberów FGD. Wykonano testy laboratoryjne, które polegały na umieszczeniu próbki w roztworze o zadanej temperaturze na 24 godziny. Przyjęto temperaturę początkową $90^{\circ} \mathrm{C}$, a następnie zwiększano o $5^{\circ} \mathrm{C}$ w kolejnym badaniu, aż do pojawienia się wżerów korozyjnych. Za miarę odporności na korozję wżerową przyjęto obecność w materiale ubytków korozyjnych oraz zmiany masy. Na podstawie wyników przeprowadzonych badań wyznaczono krytyczną temperaturę korozji wżerowej (CPT - ang. Critical Pitting Temperature) napoin na poziomie $100^{\circ} \mathrm{C}$.

Słowa kluczowe: korozja wżerowa; odporność korozyjna napoin; nadstop niklu; Alloy 59

\begin{abstract}
This article presents the results of pitting corrosion resistance tests of padding welds made of nickel superalloy Alloy 59 in a Green Death solution, which simulate FGD scrubber environment. In the laboratory tests the specimens were placed in the solution at a given temperature per 24 hours. The initial temperature was set at $90^{\circ} \mathrm{C}$ and then increased by $5^{\circ} \mathrm{C}$ in the next test, until corrosion pits appeared. A visual examination of specimens surfaces, along with mass loses were performed to characterize the pitting resistance of material. On the basis of the results, the critical pitting temperature (CPT) of padding welds at a level of $100{ }^{\circ} \mathrm{C}$ was determined.
\end{abstract}

Keywords: pitting corrosion; corrosion resistance of padding welds; nickel superalloy; Alloy 59

\section{Wstęp}

Polska przyjmując dyrektywy Unii Europejskiej, dotyczące redukcji emisji gazów cieplarnianych do atmosfery (pakiet klimatyczno-energetyczny 3 x 20\%, „Energy Roadmap 2050"), zobowiązała się do modernizacji przemysłu energetycznego. Zasadniczym paliwem dla elektrowni oraz elektrociepłowni w Polsce jest węgiel kamienny, dlatego wymagane jest, aby ze spalin kotłowych usuwać pyły, $\mathrm{NO}_{\mathrm{x}}, \mathrm{SO}_{2}, \mathrm{SO}_{3}$ i rtęć [1]. W tym celu stosuje się różnego rodzaju urządzenia, np. elektrofiltry do usuwania pyłów, instalacje do selektywnej redukcji katalitycznej (SCR), skrubery FGD (ang. flue gas desulfurization) do odsiarczania spalin na mokro lub sucho.

Materiały stosowane do budowy skruberów FGD dobierane są w zależności od działania czynników korozyjnych, warunków pracy, konstrukcji instalacji oraz aspektów ekonomicznych. Najczęściej stosuje się stale nierdzewne austenityczne (typu 317LMN, 904L) oraz stale duplex (np. 2205, 2507), rzadziej nadstopy niklu (m.in. Inconel 625, Alloy C-276, Alloy 59), które stosowane są w najcięższych warunkach eksploatacyjnych [2]. Wzajemne oddziaływanie chlorków, kwasów, wysokiej temperatury oraz stosowanej technologii odsiarczania decyduje o agresywności mediów korozyjnych takich jak ciecz w zraszaczu i w absorberze lub skropliny z oczyszczonego gazu.

Najczęściej spotykanymi typami korozji występującymi w środowisku odsiarczania jest korozja wżerowa oraz szczelinowa [3]. O odporności korozyjnej materiału decyduje w głównej mierze jego skład chemiczny. Wpływ pierwiastków stopowych na odporność na korozję wżerową można oszacować stosując tzw. równoważnik odporności wżerowej PRE (ang. pitting resistance equivalent), który oblicza się ze wzoru [2]:

$$
\mathrm{PRE}=\% \mathrm{Cr}+3,3 \% \mathrm{Mo}+16 \% \mathrm{~N}
$$

Im wyższy wskaźnik PRE, tym wyższa odporność stopu na korozję wżerową. Przyjmuje się, że materiały posiadające wartość PRE powyżej 40 mogą być stosowane w środowisku siarkowym [4,5]. Dla nadstopu Alloy 59 wartość PRE wynosi 76.

Bardziej precyzyjnym sposobem określenia odporności na korozję wżerową jest wykonanie testów korozyjnych dla określenia krytycznej temperatury korozji wżerowej (CPT).

Mgr inż. Anna Kamela, dr hab. inż. Janusz Adamiec, prof. PŚl - Politechnika Śląska.

Autor korespondencyjny/Corresponding author: anna.kamela@polsl.pl 
Jednym ze sposobów jest test w roztworze "Green Death" o składzie $7 \% \mathrm{H}_{2} \mathrm{SO}_{4}+3 \% \mathrm{HCl}+1 \% \mathrm{FeCl}_{3}+1 \% \mathrm{CuCl}_{3}$. Jest to syntetyczny roztwór symulujący środowisko pracy charakterystyczne dla skruberów FGD. W literaturze można znaleźć informacje, że dla stopu Alloy 59 wartość CPT wyznaczona w roztworze "Green Death" wynosi ponad $120{ }^{\circ} \mathrm{C}$ (powyżej tej temperatury następuje rozpad chemiczny roztworu) [6]. Jednak nie ma danych na temat odporności na korozję wżerową złączy spawanych oraz napoin. Jest to odrębne zagadnienie, które powinno zostać uwzględnione na etapie projektowania układów instalacji odsiarczania spalin, aby zapewnić ich efektywną eksploatację.

\section{Materiał do badań}

Badaniom poddano 6 próbek $z$ nadstopu niklu Alloy 59 (NiCr23Mo16Al) o wymiarach $25 \times 50 \times 2 \mathrm{~mm}$ napawanych ręcznie procesem TIG (141) w osłonie argonu (I1 wg PN-EN ISO 14175). Skład chemiczny stopu Alloy 59 zgodnie z ISO 15156 przedstawiono w tablicy I. Zastosowano materiał dodatkowy do napawania o oznaczeniu zgodnym z EN ISO 18274:S Ni 6059 (NiCr23Mo16). Przed procesem napawania powierzchnię blachy dokładnie oczyszczono poprzez szlifowanie. Proces prowadzono z prędkością $30 \mathrm{~cm} / \mathrm{min}$ przy natężeniu prądu 70 A i natężeniu przepływu gazu 10 l/min. Ilość wprowadzonego ciepła obliczona wg PN-EN 1011-1 wyniosła 0,6 kJ/cm.

Próbki wykonano w celu zbadania odporności na korozję złączy spawanych, a wykonane napoiny odwzorowywały grań spoiny. W skruberach FGD to właśnie ta część złącza spawanego wraz z przyległą SWC jest poddana oddziaływaniu środowiska korozyjnego.

\section{Metodyka i wyniki}

Badania odporności na korozję wżerową wykonano zgodnie ze zmodyfikowanym standardem ASTM G48C w roztworze "Green Death". Miały one na celu określenie odporności napoin na działanie agresywnego środowiska, charakterystycznego dla warunków pracy skruberów FGD. Próbki umieszczano $w$ roztworze na czas $24 \mathrm{~h}$. Jako temperaturę początkową dla pierwszej próbki przyjęto $90^{\circ} \mathrm{C}$. Po wykonaniu testu mierzono zmianę masy próbki oraz obserwowano powierzchnię napoiny na mikroskopie stereoskopowym przy powiększeniu 20x. Jeżeli nie zaobserwowano pojawienia się wżerów korozyjnych, zwiększano temperaturę testu o $5{ }^{\circ} \mathrm{C}$ stosując nową próbkę do badań. Jako miarę odporności na korozję wżerową przyjęto zmiany masy próbek oraz obecność uszkodzeń w materiale. Jako kryterium akceptacji przyjęto, że ubytek masy nie powinien przekraczać $5 \mathrm{mg} / \mathrm{cm}^{2}$. Próbki po badaniu pokazano na rysunkach $1 \div 3$. Zmiany masy próbek przedstawiono na rysunku 4.

W celu oceny wżerów korozyjnych, powstałych w materiale poddanemu działaniu roztworu w temp. $120^{\circ} \mathrm{C}$, analizowaną powierzchnię obserwowano na elektronowym mikroskopie skaningowym Hitachi S-3400N (rys. 5). Za pomocą spektrometru EDS, sprzężonego z SEM, wykonano mikroanalizę składu chemicznego w obszarze napoiny oraz materiału rodzimego (rys. 5, tabl. II).

Tablica I. Skład chemiczny stopu Alloy 59 (\% mas.) zgodnie z ISO 15156 [6] Table I. Chemical composition of Alloy 59 (wt \%) according to ISO 15156 [6]

\begin{tabular}{|c|c|c|c|c|c|c|c|c|c|c|c|c|}
\hline & $\mathrm{Fe}$ & $\mathrm{Cr}$ & $\mathrm{Ni}$ & Mo & C & S & $\mathrm{Mn}$ & Si & $\mathrm{Cu}$ & $\mathbf{P}$ & Al & Co \\
\hline Min. & - & 22,0 & \multirow{2}{*}{ osnowa } & 15,0 & - & - & - & - & - & - & 0,1 & - \\
\hline Max. & 1,5 & 24,0 & & 16,5 & 0,01 & 0,01 & 0,5 & 0,1 & 0,5 & 0,015 & 0,4 & 0,3 \\
\hline
\end{tabular}
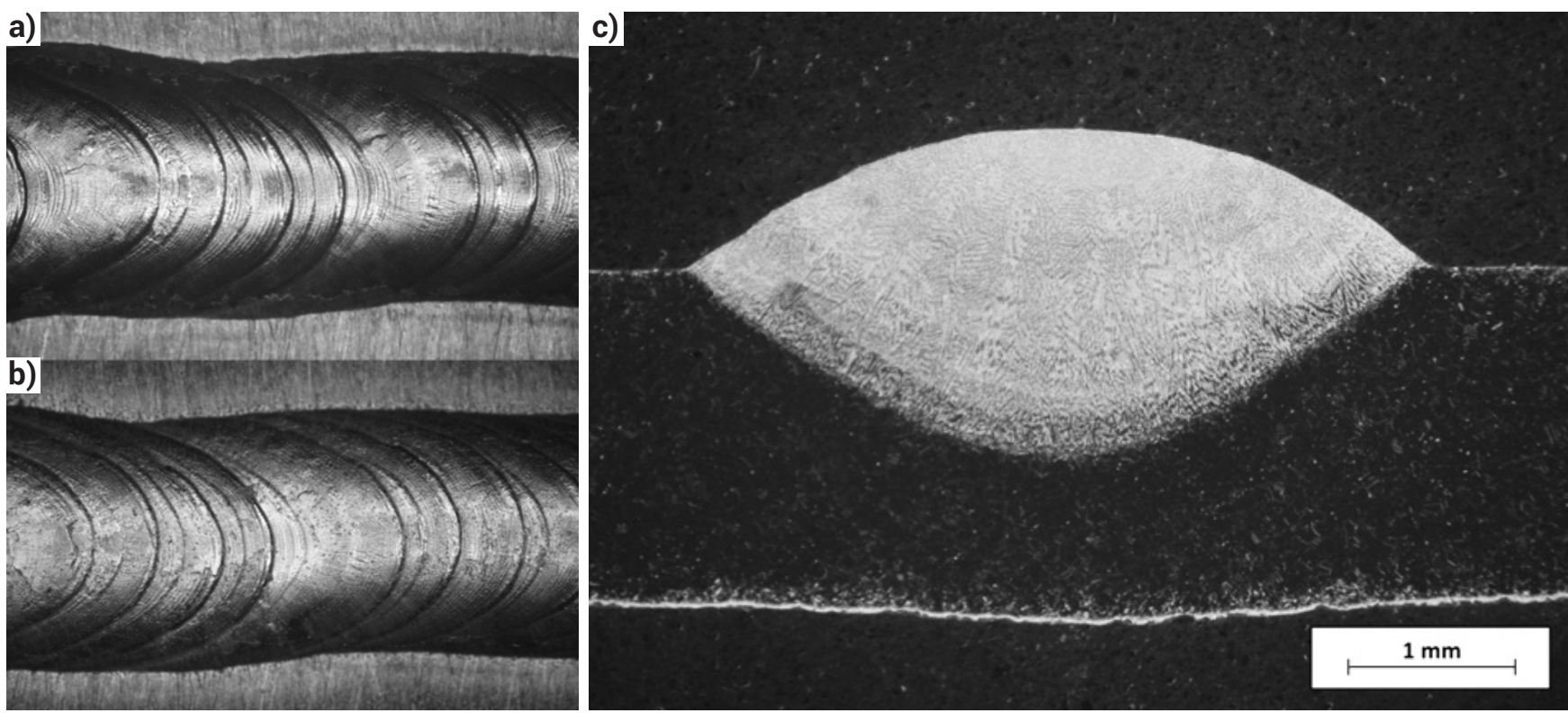

Rys. 1. Napoiny po teście korozyjnym w roztworze "Green Death" w temp. $90{ }^{\circ} \mathrm{C}$ : a) powierzchnia przed testem, b) powierzchnia po teście, c) przekrój napoiny

Fig. 1. Padding welds after a corrosion test in a "Green Death" solution at $90{ }^{\circ} \mathrm{C}$ : a) surface before testing, b) surface after testing, c) cross-section of the padding weld 

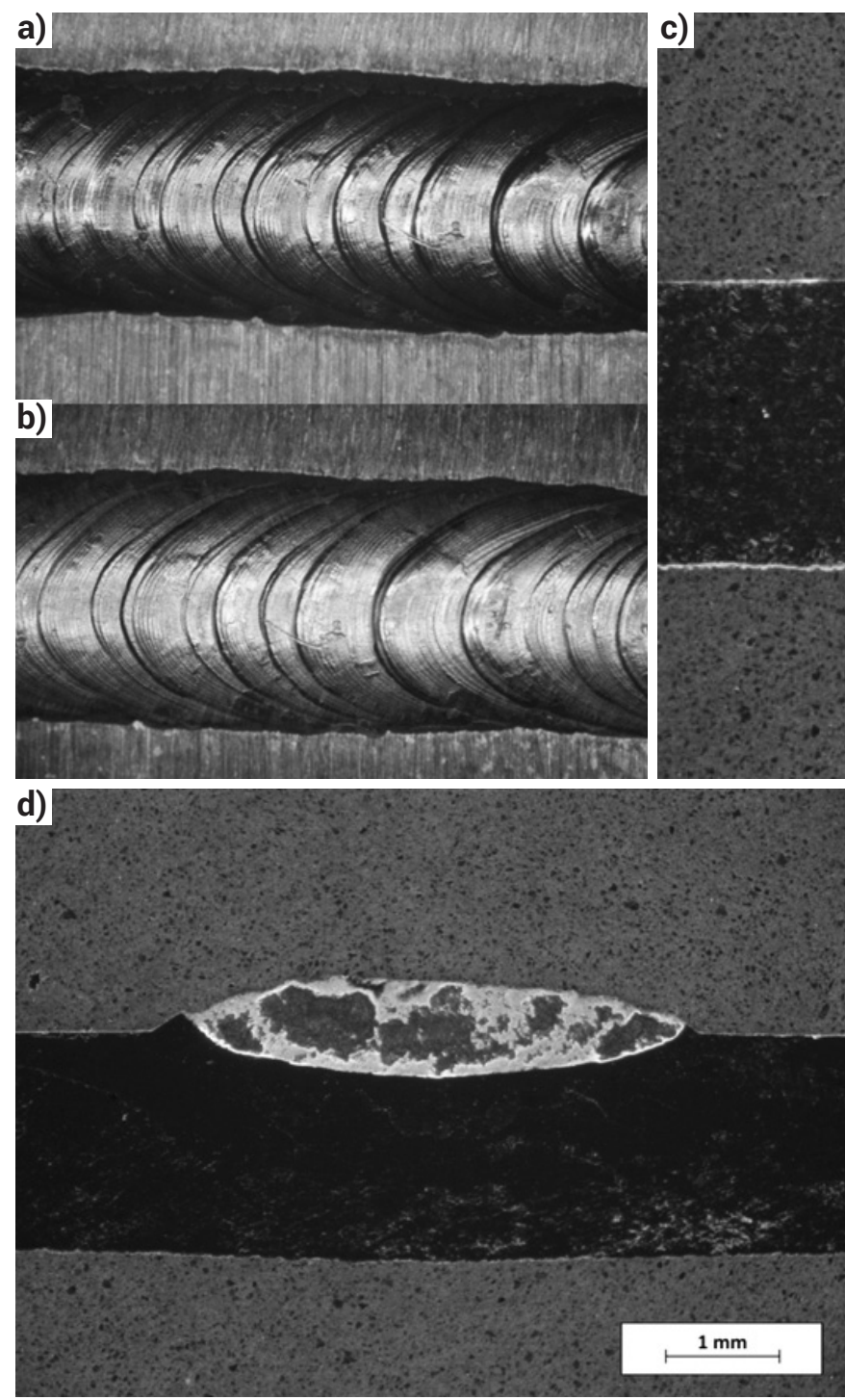

Rys. 2. Napoiny po teście korozyjnym w roztworze "Green Death” w temp. $105^{\circ} \mathrm{C}$ : a) powierzchnia przed testem, b) powierzchnia po teście, c) przekrój napoiny, d) i e) wżery w napoinie w miejscu niepełnego wtopienia

Fig. 2. Padding welds after a corrosion test in a "Green Death" solution at $105{ }^{\circ} \mathrm{C}$ : a) surface before testing, b) surface after testing, c) cross-section of the padding weld, d) and e) the corrosion pits in the padding weld in place of incomplete penetration
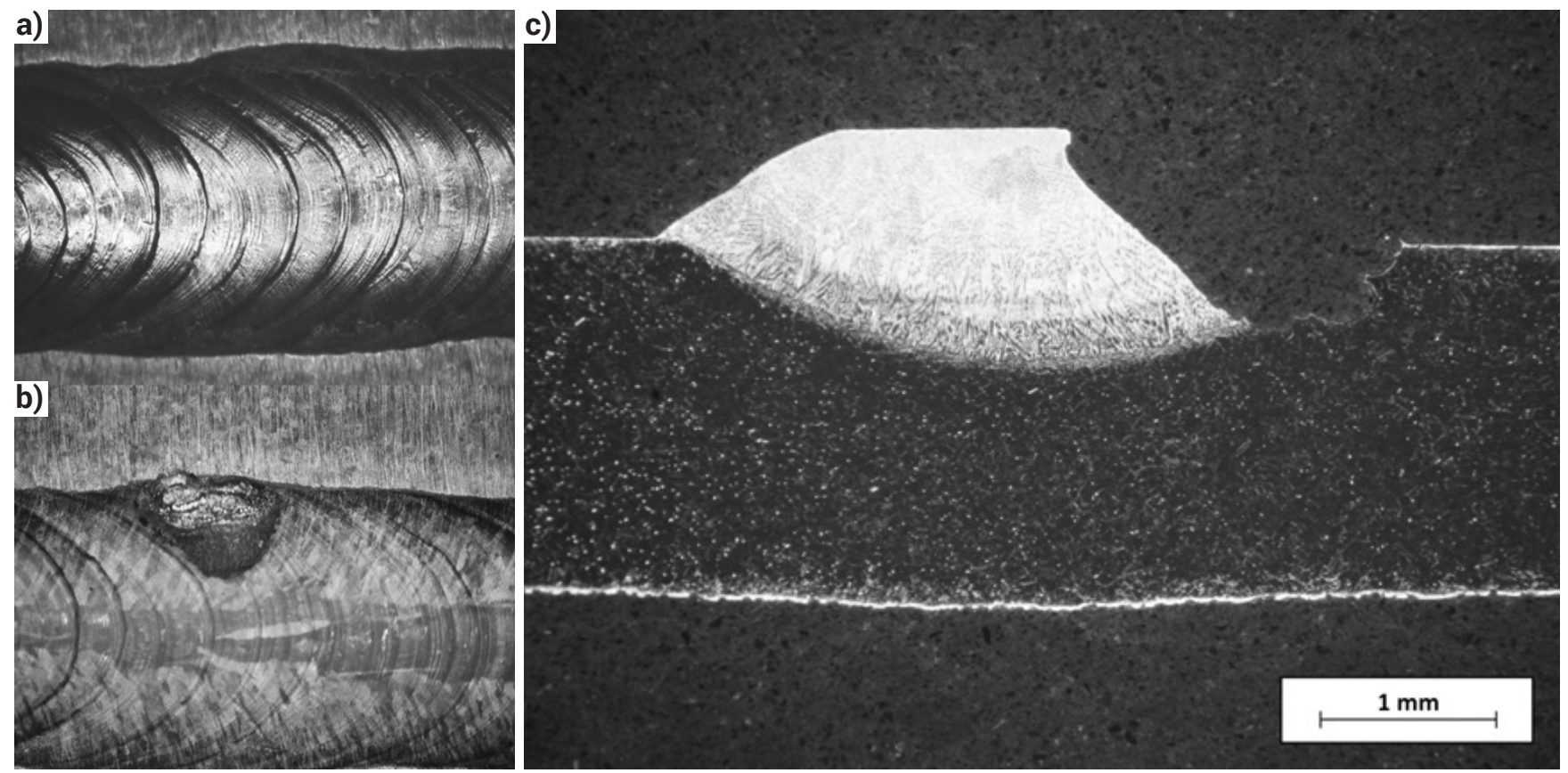

Rys. 3. Napoiny po teście korozyjnym w roztworze "Green Death" w temp. $120^{\circ} \mathrm{C}$ : a) powierzchnia przed testem, b) powierzchnia po teście, c) przekrój napoiny z widocznym wżerem korozyjnym

Fig. 3. Padding welds after a corrosion test in a "Green Death" solution at $120^{\circ} \mathrm{C}$ : a) surface before testing, b) surface after testing, c) cross-section of the padding weld with visible corrosion pit 


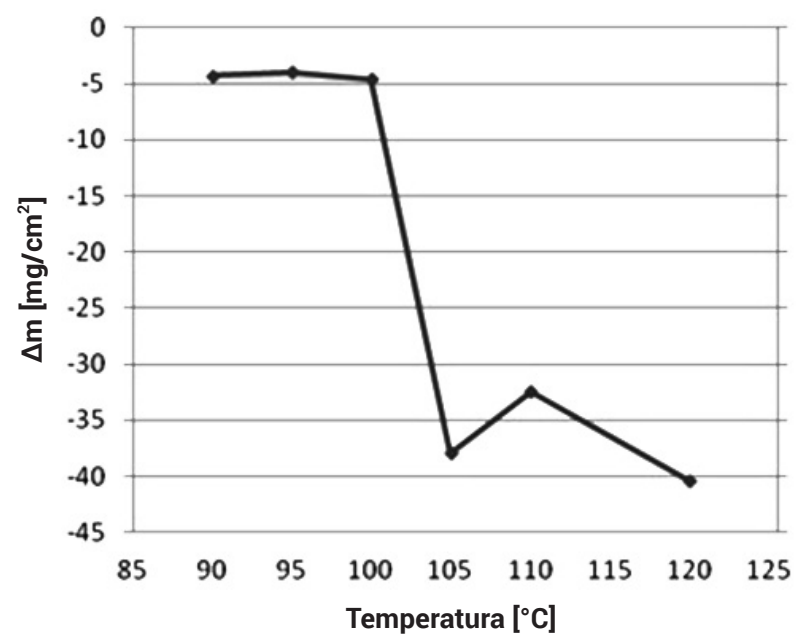

Tablica II. Wyniki analizy składu chemicznego (EDS) na powierzchni wżeru (\% mas.)

Table II. The results of chemical composition microanalysis (EDS) on the pitting surface

\begin{tabular}{|c|c|c|c|c|c|c|c|c|}
\hline & Al & $\mathbf{S i}$ & $\mathbf{S}$ & $\mathbf{C l}$ & $\mathbf{C r}$ & $\mathbf{M n}$ & $\mathbf{N i}$ & Mo \\
\hline 1 - NAPOINA & 0,4 & - & - & 0,4 & 23,9 & - & 61,7 & 13,6 \\
\hline 2 - MR & 0,5 & 1,6 & 0,4 & 2,7 & 21,7 & 0,4 & 57,0 & 15,7 \\
\hline
\end{tabular}

Rys. 4. Zmiany masy próbek w teście odporności na korozję wżerową Fig. 4. The mass changes of the specimens in pitting corrosion resistance test

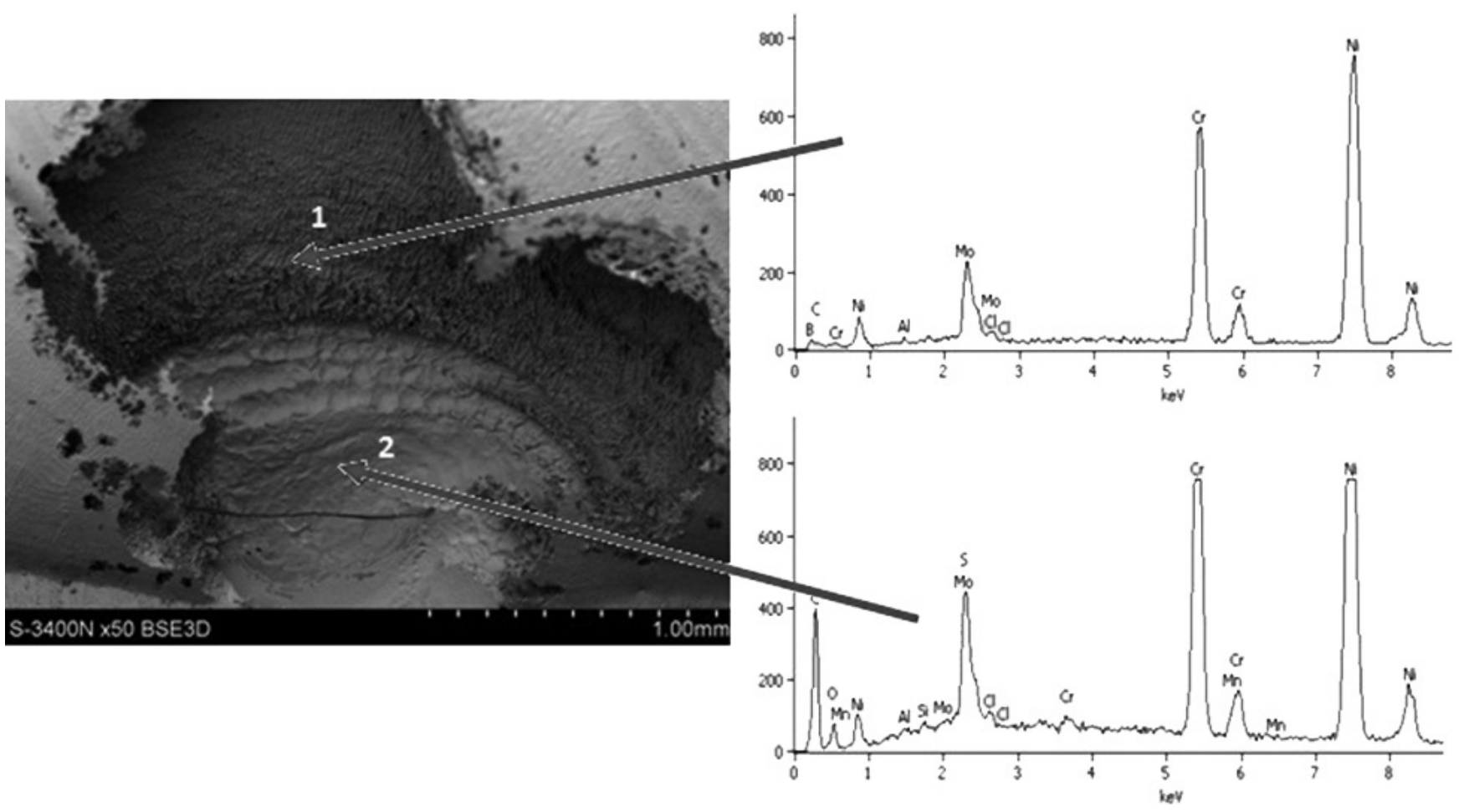

Rys. 5. Struktura napoiny w miejscu powstania wżeru z wynikami mikroanalizy składu chemicznego EDS

Fig. 5. Microstructure of the padding weld at the pitting site with the results of chemical composition microanalysis (EDS)

\section{Podsumowanie}

Celem wykonanych badań było określenie skłonności do powstawania wżerów korozyjnych w napoinach wykonanych ze stopu Alloy 59. Analizowano wielkość i miejsca powstawania wżerów oraz ubytek masy. Po ekspozycji próbek w syntetycznym roztworze FGD przez 24 godziny w temperaturze do $100^{\circ} \mathrm{C}$ nie zaobserwowano powstawania wżerów w materiale (rys. 1), a zmiany masy były stosunkowo niewielkie (ok. $4,8 \mathrm{mg} / \mathrm{cm}^{2}$ ). Dla próbki narażonej na działanie kwasu w temperaturze $105^{\circ} \mathrm{C}$ zanotowano ubytek masy ok. $38 \mathrm{mg} / \mathrm{cm}^{2}$ (rys. 4). Na powierzchni SWC widoczne są pojedyncze wżery (rys. 2b). Jednak podczas obserwacji przekroju napoiny ujawniono miejsca, w których jej powierzchnia nie została uszkodzona, ale wżery powstały wewnątrz materiału. Zjawisko to zaobserwowano w miejscu niepełnego wtopienia napoiny (rys. $2 \mathrm{~d}, 2 \mathrm{e}$ ). Po ekspozycji próbki w temp. $120^{\circ} \mathrm{C}$ widoczne są wżery korozyjne od powierzchni w głąb materiału. Na przekroju poprzecznym (rys. 3c) można zaobserwować, że obejmują one nie tylko napoinę i strefę wpływu ciepła, ale również materiał rodzimy w pobliżu SWC. Na podstawie analizy składu chemicznego EDS stwierdzono obecność na powierzchni wżerów chloru i siarki (tabl. II). 
Powstawanie osadów z produktów reakcji (np. chlorków) w okolicy wżerów jest charakterystycznym zjawiskiem w procesie korozji wżerowej. Korozja wżerowa najczęściej pojawia się w miejscu występowania niejednorodności wewnętrznych materiału (wtrącenia, porowatość, brak przetopienia) oraz zewnętrznych (zarysowania, resztki zgorzeliny, osady). Stąd ważne jest, aby zapewnić wysoką jakość napoin, w celu uniknięcia występowania niezgodności. Na podstawie wyników z przeprowadzonych badań oraz przyjętego poziomu akceptacji dla ubytku masy wyznaczono krytyczną temperaturę korozji wżerowej (CPT) napoin z nadstopu niklu Alloy 59 na poziomie $100^{\circ} \mathrm{C}$.

\section{Literatura}

[1] Hernas A.: Uwarunkowania rozwoju krajowej energetyki, Materiały i technologie stosowane w budowie kotłów nadkrytycznych i spalarni odpadów, wyd. SITPH, Katowice, 2009.

[2] Vangeli P., Torsner E., Beckers B., Carinci G.M.: Stale nierdzewne do skruberów w IOS - I część, Nowa Energia, 04, 2009, s. 91-95.

[3] Alves H., Werner H., Agarwal D.C.: Corrosion performance and applications of Alloy 31 and Alloy 59 in sulfuric acid media, Corrosion 2006, Paper 06222, NACE International.
[4] Wang H.S.: Effect of Welding Variables on Cooling Rate and Pitting Corrosion Resistance in Super Duplex Stainless Weldments, Materials Transactions, Vol. 46, No. 3, 2005, pp. 593-60.

[5] Alves H., Kurumlu D., Behrens R.: A new developed Ni-Cr-Mo alloy with improved corrosion resistance in flue gas desulfurization and chemical process applications, Corrosion 2013, Paper 2325, NACE International.

[6] Material Data Sheet No. 4130: VDM Alloy 59, August 2017. 